http://dx.doi.org/10.32929/2446-8355.2019v28n2p138-151

\title{
APLICAÇÃO DE ACIBENZOLAR-S-METHYL EM TRIGO NO CONTROLE ALTERNATIVO DE Gibberella zea
}

\author{
Daniele Cristina Fontana ${ }^{1 *}$, Stela Maris Kulckzinsky ${ }^{2}$, Thais Pollon Zanatta ${ }^{3}$, Marcos Vinícius \\ Marques Pinheiro ${ }^{4}$, Juliano Cesar da Silva ${ }^{5}$
}

\footnotetext{
${ }^{1}$ Doutoranda no Departamento de Produção Vegetal na Escola Superior em Agricultura Luiz de Queiroz Universidade de São Paulo, Piracicaba/SP; * E-mail do autor correspondente: daani_fontana@hotmail.com.

${ }^{2}$ Professora Doutora no Departamento de Ciências Agrárias e Ambientais, Universidade Federal de Santa Maria, Campus Frederico Westphalen, Frederico Westphalen - RS.

${ }^{3}$ Professora Mestre no Departamento de Agronomia, Centro de Ensino Superior Riograndense, Sarandi - RS.

${ }^{4}$ Pós doutorado no Programa de Pós-graduação em Agronomia, Agricultura e Ambiente pela Universidade Federal de Santa Maria, Campus Frederico Westphalen, Frederico Westphalen - RS.

${ }^{5}$ Mestrado no Programa de Pós-Graduação em Agronomia, Agricultura e Ambiente pela Universidade Federal de Santa Maria, Campus Frederico Westphalen, Frederico Westphalen - RS.
}

Recebido: 24/10/2018; Aceito: 02/05/2019

RESUMO: O objetivo deste trabalho foi determinar a dose, época e número de aplicação ideais de ácido metil salicílico (ASM) para o controle da giberela durante a antese e sua influência sobre as características agronômicas da cultura do trigo. $O$ delineamento experimental utilizado foi de blocos casualizados, em esquema fatorial triplo $2 \times 3 \times 4$, sendo duas cultivares de trigo, três épocas de aplicação e quatro doses, com três repetições. Avaliouse o tamanho da espiga, peso da espiga, número de grãos por espiga, número de espiguetas estéreis por espiga, incidência e severidade de giberela, peso de mil grãos e produtividade. As variáveis analisadas foram submetidas à análise de variância e quando significativas os fatores qualitativos foram submetidas à comparação de médias pelo teste Tukey a $5 \%$ de probabilidade, e para os fatores quantitativos, realizou-se a análise de regressão. Duas aplicações de ASM, realizadas no início + $1 / 2$ da antese condicionam menor número de espiguetas estéreis na cultura do trigo. A dose de 37,5 $\mathrm{g} \mathrm{ha}^{-1}$ de ASM proporciona baixos percentuais de incidência e severidade de giberela em grãos de trigo, sugerindo inserção do ASM no manejo integrado da doença. A dose de 12,5 $\mathrm{g} \mathrm{ha}^{-1}$ de ASM condiciona incremento na produtividade de trigo.

Palavras-chave: Triticum aestivum. Indutor de resistência. Manejo integrado.

\section{APPLICATION OF ACIBENZOLAR-S-METHYL IN WHEAT IN ALTERNATIVE CONTROL OF Gibberella zea}

\begin{abstract}
The objective of this work was to determine the ideal dose, time and number of application of methyl salicylic acid (ASM) for the control of gibberella during anthesis and its influence on the agronomic characteristics of the wheat crop. The experimental design was a randomized complete block design, in a $2 \times 3 \times 4$ triple factorial scheme, being two wheat cultivars, three application times and four doses, with three replicates. Spike size, ear weight, number of grains per spike, number of sterile spikelets per spike, incidence and severity of
\end{abstract}


giberela, weight of a thousand grains and yield were evaluated. The analyzed variables were submitted to analysis of variance and when significant the qualitative factors were submitted to the comparison of means by the test Tukey to $5 \%$ of probability, and for the quantitative factors, the regression analysis was performed. Two applications of ASM, carried out at the beginning $+1 / 2$ of the anthesis, condition fewer sterile spikelets in the wheat crop. The dose of $37.5 \mathrm{~g} \mathrm{ha}^{-1}$ of ASM provides low percentages of incidence and severity of giberela in wheat grains, suggesting ASM insertion into the integrated management of the disease. The $12.5 \mathrm{~g}$ $\mathrm{ha}^{-1}$ dose of ASM causes an increase in wheat yield.

Key words: Triticum aestivum. Resistance inducer. Integrated management.

\section{INTRODUÇÃO}

O trigo (Triticum aestivum L.) é uma das principais culturas alimentares, sendo cultivado em diversos ambientes e regiões geográficas, contudo, cerca de $90 \%$ da produção de trigo está concentrado na região Sul do Brasil (CONAB, 2019). Seu rendimento está relacionado às condições de cultivo como solo, clima, manejo da cultura e cultivar utilizada (QUEIROZ et al., 2015). No entanto, a ocorrência de doenças contribui para a limitação da produtividade do trigo, sendo favorecidas pelo excesso de chuvas, com períodos longos e frequentes de molhamento foliar e por temperaturas elevadas.

A doença giberela, causada pelo fungo Gibberella zea (Schw.) Petch está entre as doenças com maior potencial de danos em cereais de inverno, e de ocorrência nas principais regiões tritícolas do mundo (DEL PONTE et al., 2015). No Brasil, em um período de mais de duas décadas foram estimados em média de 18,62\% de danos na produtividade, contudo, ressalta-se a grande variação de seus percentuais em ocasião do ano de cultivo (CASA et al., 2011). Outros danos ocorrem na qualidade do produto final principalmente devido a presença de micotoxinas produzidas pelo fungo (TRALAMAZZA et al., 2016), e o seu acúmulo nos grãos de trigo representam riscos de toxicidade aos seres humanos e animais.

Dentre as práticas de manejo, o uso dos fungicidas tem sido intensificado, sendo atualmente considerada uma das principais táticas no manejo de G. zeae em trigo, juntamente com o uso de cultivares com menor susceptibilidade (GILBERT; HABER, 2013). O controle da doença através de pulverizações de produtos químicos, na maioria das vezes torna-se ineficiente em virtude de vários fatores, como desuniformidade na emergência das espigas e das anteras (principal alvo de proteção), dificuldade de distribuição uniforme das gotas nas anteras e, em algumas vezes, atraso na aplicação devido às condições climáticas quando as infecções já estão estabelecidas (SPOLTI; DEL PONTE, 2013). Esses fatores, aliados ao uso contínuo dos mesmos princípios ativos tem proporcionado decréscimo na produtividade e qualidade do produto final (GILBERT; HABER, 2013), além de aumentar o risco de surgimento de populações fúngicas resistentes, principalmente no caso de fungicidas sistêmicos, em que apresentam um sítio de ação específico (LUCAS et al., 2015).

A redução da sensibilidade de G. zeae constatada para triazóis (KLIX et al., 2007) e o aumento da contaminação de micotoxinas com a utilização de estrobilurinas (WEGULO, 2012), associada a redução da eficiência de misturas duplas de triazóis para seu controle 
(PAUL et al., 2008) tornam a utilização de fungicidas uma opção que deve ser manejada para que o controle de doenças seja eficiente.

Para que o controle de doenças seja eficiente, recomenda-se a utilização de ferramentas do manejo integrado; dentre as quais se destaca a utilização de acibenzolar-metil salicílico (ASM), um indutor de resistência análogo ao ácido salicílico (AS) (MEDOZA et al., 2018). Este indutor atua na indução da biossíntese de enzimas envolvidas na formação de compostos de defesa vegetal, e proteínas relacionadas a patogenicidade (OLIVEIRA et al., 2016). Resultados positivos com a utilização do ASM já foram verificados em plantas de Arabdopsis, demonstrando aumento da síntese de AS e substâncias de defesa, aumentando a expressão de genes relacionados à resistência de Fusarium sp. (MAKANDAR et al., 2012). Outros resultados com a aplicação de ASM já foram constatados em diversos trabalhos (BERTONCELLI et al., 2016; BERTONCELLI et al., 2015; CAMPOS et al., 2009; CHAIN et al., 2009). No entanto, a eficiência de ASM para controle da G. zeae na cultura do trigo na região Sul do Brasil não está totalmente elucidada.

Dessa forma, o trabalho teve como objetivo determinar a época, dose e número de aplicações ideais de ácido metil salicílico (ASM) para controle de Gibberella zea durante a antese e sua influência sobre as características agronômicas da cultura do trigo.

\section{MATERIAL E MÉTODOS}

O experimento foi conduzido na área experimental da Universidade Federal de Santa Maria, Campus Frederico Westphalen - RS, coordenadas $27^{\circ} 39^{\prime} \mathrm{S}$ e $53^{\circ} 42^{\prime} \mathrm{W}$ e com altitude de 488 m. Segundo a classificação de Köppen, o clima é do tipo 3, subtropical úmido, com precipitação média anual de 2100 mm. O solo da região, de acordo com a EMBRAPA (2013), é classificado como Latossolo vermelho.

O delineamento experimental utilizado foi o de blocos casualizados (DBC), em esquema fatorial triplo $2 \times 3 \times 4$, sendo duas cultivares de trigo (BRS 374 e SINUELO), três épocas de aplicação de Acibenzolar-S-Metil [1 - Início do florescimento (Início), 2 Florescimento completo na parte apical da espiga (1/2), 3 - Florescimento completo na parte basal da espiga (Início + 1/2)] e quatro doses $\left(0,0 ; 12,5 ; 25\right.$ e 37,5 $\mathrm{g} \mathrm{ha}^{-1}$ do produto comercial Bion ${ }^{\circledR}$ ), mais o controle químico, com três repetições, sendo cada unidade experimental constituída de cinco linhas de semeadura, espaçadas $0,17 \mathrm{~m}$ entre si, e 3,5 m de comprimento.

As cultivares de trigo utilizadas foram BRS 374 e SINUELO, sendo caracterizadas como suscetíveis e moderadamente suscetíveis à infecção por G. zeae, de acordo com Cairão et al. (2013) e Biotrigo genética (2012), respectivamente. As épocas de aplicação testadas seguiram a escala fenológica da cultura, sendo no período de florescimento, correspondente a antese (a partir do início do florescimento) o período recomendado para realização de controle, pois as anteras encontram-se completamente expostas. Utilizou-se o Bion 500WG ${ }^{\circledR}$ (Acibenzolar-S-Metílico $500 \mathrm{~g} \mathrm{~kg}^{-1}$ do ingrediente ativo - i.a), um análogo ao ácido salicílico (AS); no entanto, está recomendado para a cultura do trigo no controle do oídio na dose de 25 $\mathrm{g} \mathrm{ha}^{-1}$ (BRASIL, 2018). As pulverizações foram realizadas de forma manual com pulverizador 
de pressão constante gerada por gás $\mathrm{CO}_{2}$, utilizando bico tipo cone vazio, de modo que a pulverização permitisse boa cobertura de plantas, sendo realizada uma aplicação por época.

A semeadura do trigo ocorreu no dia 17 de junho de 2015 no sistema de plantio direto em sucessão à cultura da soja, com densidade populacional de aproximadamente 350 plantas $/ \mathrm{m}^{2}$. Os tratos culturais seguiram as Indicações Técnicas para a Cultura do Trigo (REUNIÃO, 2005). O ponto de colheita foi atingido no dia 7 de novembro de 2015, após 120 dias da semeadura, e a infecção ocorreu sob condições naturais. Os elementos meteorológicos, referentes à temperatura, umidade e precipitação, foram coletados através da estação meteorológica do INMET situada no Campus da UFSM - Frederico Westphalen/RS (Figura 1).

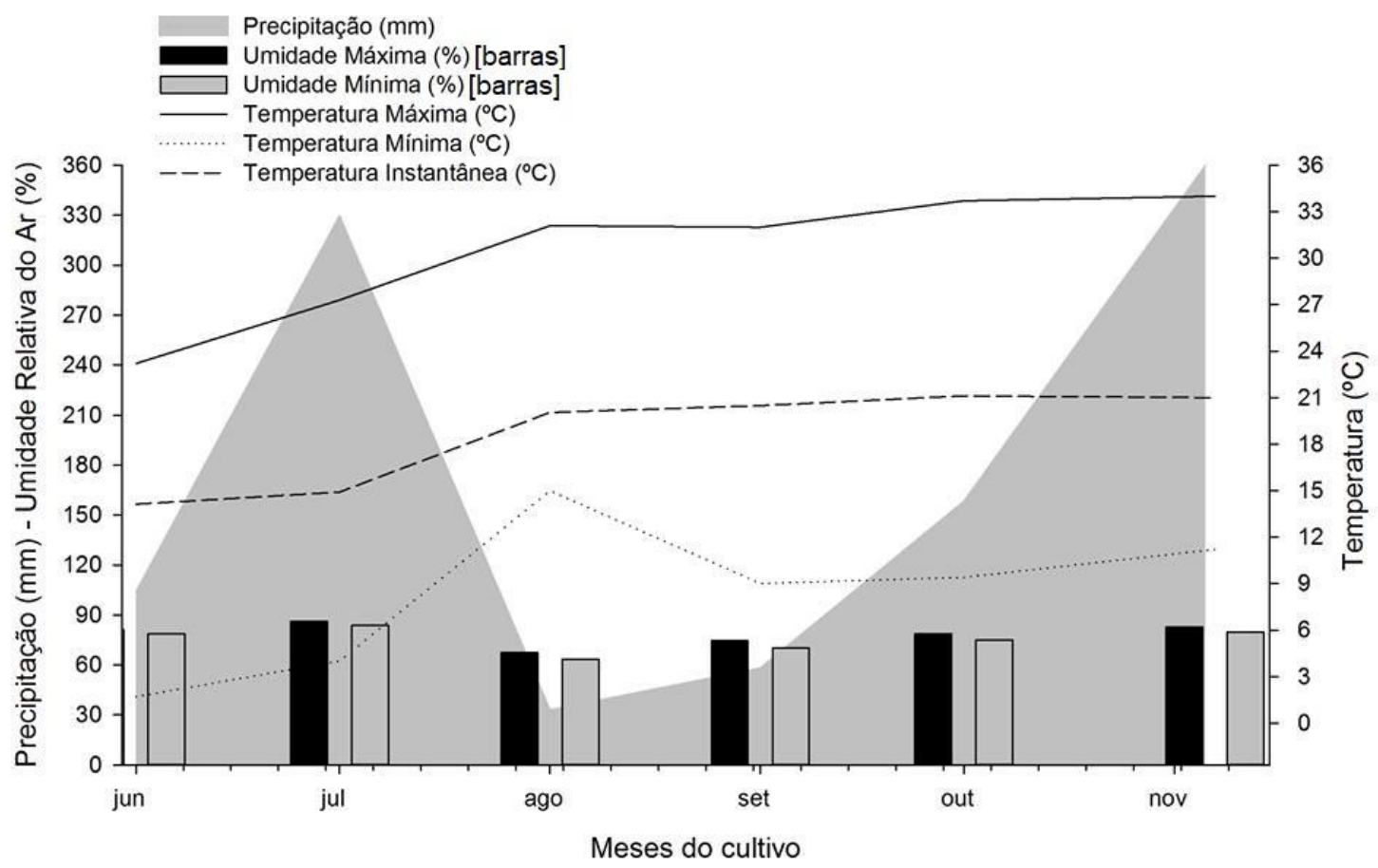

Figura 1. Dados meteorológicos de precipitação diária $(\mathrm{mm})$, umidade do ar máxima e mínima, e temperaturas máximas, mínimas e instantâneas durante o cultivo das cultivares de trigo (Triticum aestivum), BRS 374 e Sinuelo, de junho a novembro de 2015. Fonte: INMET, (Frederico Westphalen - A854) Estação meteorológica automática de Frederico Westphalen RS. Meteorological data of daily precipitation ( $\mathrm{mm}$ ), maximum and minimum air humidity, and maximum, minimum and instantaneous temperatures during cultivation of wheat cultivars (Triticum aestivum), BRS 374 and Sinuelo, from June to November, 2015. Source: INMET, (Frederico Westphalen - A854) Frederico Westphalen automatic weather station $R S$.

Para critérios de avaliação foram descartadas duas linhas laterais e 0,5 metros em cada extremidade, perfazendo uma área útil de $1,28 \mathrm{~m}^{2}$ de espigas colhidas. O experimento foi avaliado após 120 dias da semeadura quanto ao tamanho da espiga, peso da espiga, número de grãos por espiga, número de espiguetas estéreis por espiga, incidência e severidade de $G$. zeae, peso de mil grãos e produtividade. 
Utilizou-se cinco espigas de cada amostra para realização das avaliações das variáveis, sendo que para o tamanho da espiga, realizou-se medidas com paquímetro digital a partir da base até o ápice (definida como sendo a distância $(\mathrm{cm})$ do início da ráquis até a extremidade da espiga, excluindo-se as aristas). Para o peso da espiga realizou-se a pesagem de cada espiga em balança de precisão, e os resultados expressos em gramas espiga ${ }^{-1}$. Para a variável número de espiguetas estéreis por espiga, realizou-se a contagem do número de espiguetas estéreis. Posteriormente as espigas foram trilhadas individualmente e realizada a contagem do número de grãos por espiga.

Para a incidência de G. zea foram coletadas 25 espigas, ao acaso, nas três linhas centrais de cada parcela, no estádio de maturação (EC 89). As espigas foram cortadas e levadas ao laboratório de Fitopatologia da UFSM, Campus de Frederico Westphalen - RS, e a incidência da doença foi considerada a partir da espiga que apresentava, no mínimo, uma espigueta infectada, apresentando sintomas característicos da doença. A relação entre número de espigas totais e espigas infectadas foi utilizada para cálculo da incidência, sendo dessa forma, representados em porcentagem. Para a severidade de G. zea foram realizadas a contagem de espiguetas infectadas por espiga e os dados foram expressos em porcentagem, obtidos do número médio de espiguetas gibereladas em função do número médio de espiguetas por espiga.

Para o peso de mil grãos seguiu-se a metodologia descrita na RAS (BRASIL, 2009), onde foram contadas manualmente oito repetições de 100 grãos e pesadas. Para calcular usouse a seguinte fórmula: $\mathrm{PMG}=$ (peso da amostra $\mathrm{x} 1.000) / \mathrm{n}^{\circ}$ total de grãos. Já para quantificar a produtividade foram colhidas manualmente as espigas das três linhas centrais da parcela. As espigas foram trilhadas com posterior limpeza e pesagem dos grãos com ajuste do teor de umidade para $13 \%$, e determinada a produtividade em $\mathrm{kg} \mathrm{ha}^{-1}$.

Dessa forma, para a avaliação do ASM, as variáveis analisadas foram submetidas à análise de variância e quando significativas os fatores qualitativos foram submetidas à comparação de médias pelo teste Tukey a $5 \%$ de probabilidade, e para os fatores quantitativos, realizou-se a análise de regressão. Uma análise complementar foi realizada a fim de comparar as melhores doses de ASM da análise anterior, com o fungicida recomendado para a cultura, trifloxistrobina+tebuconazole $100+200 \mathrm{~g} \mathrm{~L}^{-1}$ i.a (Nativo ${ }^{\circledR}$ ); (AGROFIT, 2018), sendo submetidas à comparação de médias pelo teste Dunnet. Todas as análises foram realizadas por meio do programa estatístico SISVAR (FERREIRA, 2000).

\section{RESULTADOS E DISCUSSÕES}

Durante o período de cultivo do experimento, verificaram-se condições variáveis de precipitação e temperatura, sendo as maiores precipitações ocorridas nos meses de junho a julho e outubro a novembro, coincidindo com as fases iniciais e finais do desenvolvimento do trigo. Também foi possível observar condições adversas de temperatura na estação inverno, ocorrendo temperaturas elevadas, com média da temperatura instantânea de $21^{\circ} \mathrm{C}$, a partir do mês de agosto; e a média das máximas alcançando $34^{\circ} \mathrm{C}$, mesmo período em que se observou florescimento das cultivares de trigo. Considerando o ciclo das cultivares de trigo, o período de florescimento ocorreu na primeira quinzena de setembro, ocorrendo temperaturas mínimas 
e máximas elevadas e precipitação com média de $50 \mathrm{~mm}$ neste mês, considerada baixa para a cultura (Figura 1).

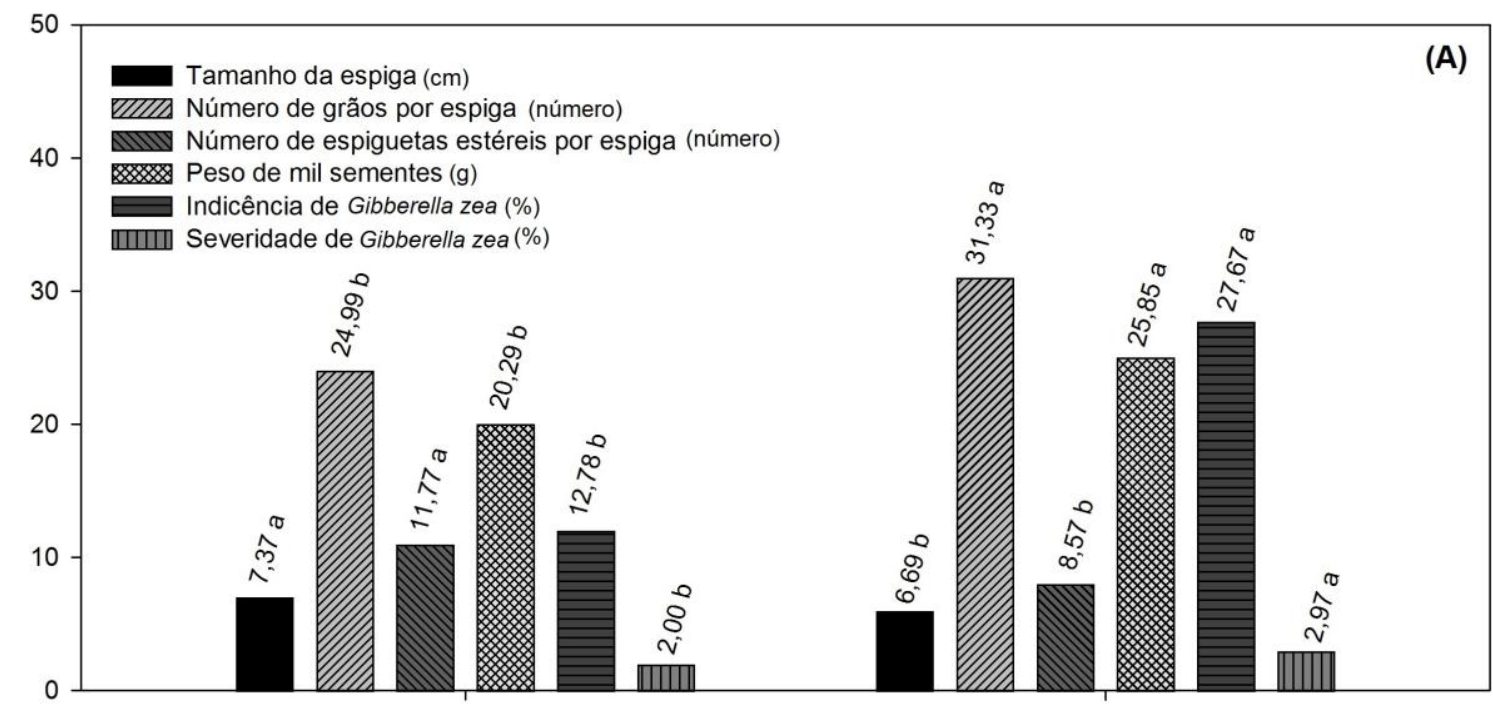

Sinuelo

BRS 374

Cultivares de trigo
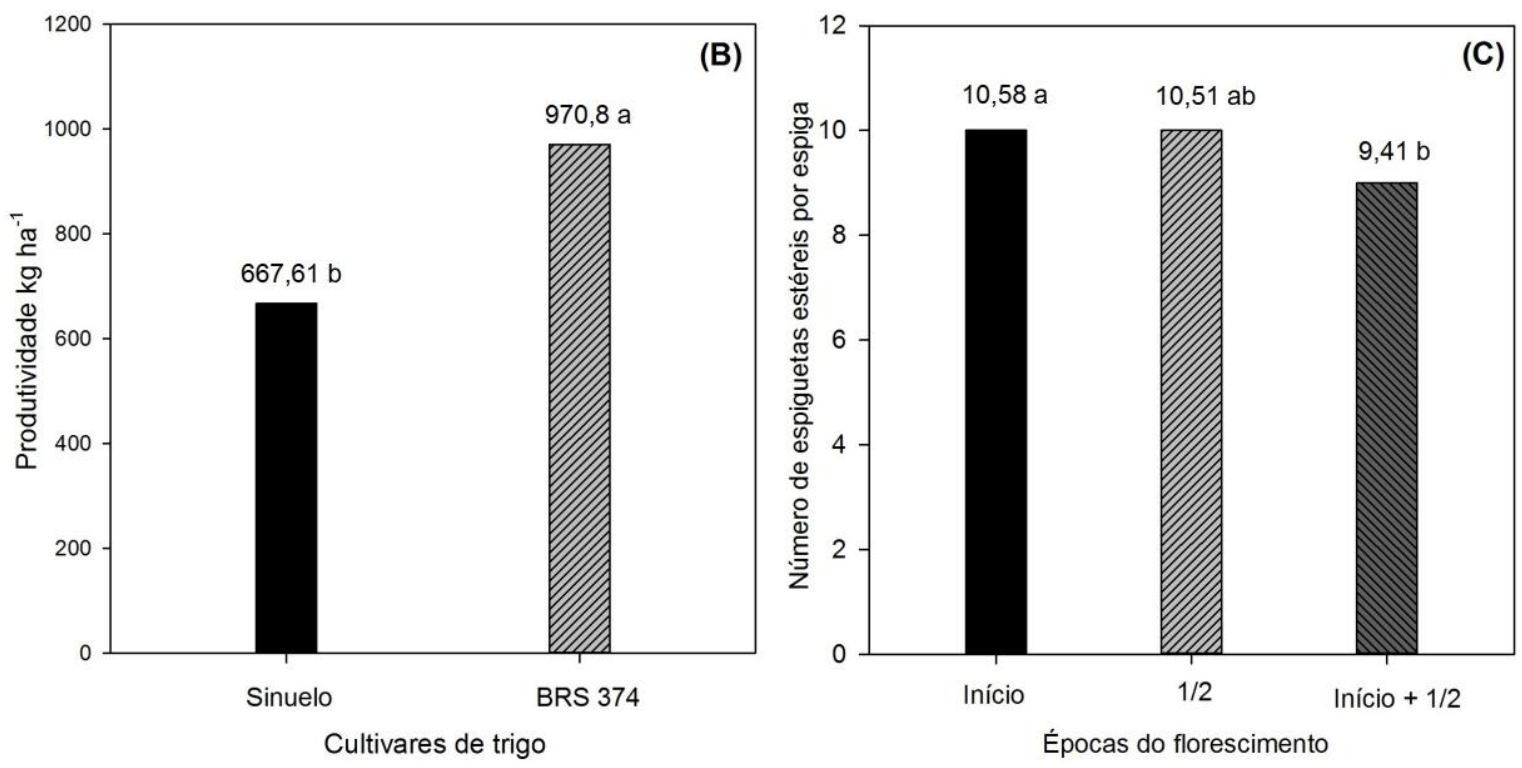

Figura 2. Tamanho de espiga $(\mathrm{cm})$, número de grãos por espiga, número de espiguetas estéreis por espiga, peso de mil sementes (gramas), incidência e severidade (\%) de Gibberella zea (A), e produtividade $\left(\mathrm{kg} \mathrm{ha}^{-1}\right)$ (B) para as cultivares Sinuelo e BRS 374; número de espiguetas estéreis por espiga para as épocas do florescimento (início, $1 / 2$ e início $+1 / 2$ ) (C), submetidas à aplicações de ASM durante a antese. Spike size, number of grains per spike, number of sterile spikelets per ear, weight of one thousand grains, incidence and severity of Gibberella zea (A), and productivity $\left(\mathrm{kg} \mathrm{ha}^{-1}\right)(B)$ for the cultivars Sinuelo and BRS 374; number of sterile spikelets per spike for flowering times (beginning, $1 / 2$ and beginning $+1 / 2$ ) (C), submitted to ASM applications during anthesis.

Pela análise de variância foi possível observar significância a 5\% de probabilidade de erro pelo teste $\mathrm{F}$, para as variáveis tamanho da espiga, número de grãos por espiga e peso de 
mil sementes, sendo significativas apenas para o fator cultivar, já as variáveis produtividade, incidência e severidade de G. zea foram significativas isoladamente para os fatores cultivares e doses. Já o número de espiguetas estéreis apresentou significância isoladamente para os fatores cultivares e épocas de aplicação. $\mathrm{O}$ peso de espiga não apresentou significância para nenhuma dos fatores analisados (Figura 2).

Para as variáveis número de grãos por espiga, peso de mil sementes (Figura 2A) e produtividade (Figura 2B), a cultivar BRS 374 (31,33; 25,85; 970,8, respectivamente) foi superior significativamente quando comparado a Sinuelo (24,99; 20,29; 667,61, respectivamente). Contudo, a cultivar BRS 374 proporcionou os maiores percentuais de incidência e severidade de G. zeae (27,67 e 2,97\%, respectivamente), quando comparado a Sinuelo $(12,78$ e $2,00 \%$, respectivamente) $(\mathrm{p}<0,05)$. Para as variáveis tamanho da espiga e número de espiguetas estéreis por espiga, a cultivar Sinuelo apresentou superioridade quando comparado a BRS $374(\mathrm{p}<0,05)$.

A produtividade de trigo verificada para a cultivar BRS 374 foi de $970,8 \mathrm{~kg} \mathrm{ha}^{-1}$, sendo superior estatisticamente à cultivar Sinuelo que alcançou produção de apenas 667,61 kg ha-1 (Figura 2B). Embora o fator épocas de aplicação de ASM não tenha influenciado a incidência e severidade de G. zeae, este interferiu no número de espiguetas estéreis por espiga. Os maiores valores de esterilidade das espiguetas foram verificados na aplicação realizada no início do florescimento $(10,58)$ não diferindo significativamente da aplicação na metade do florescimento $(10,51)$. Os menores valores foram verificados para a aplicação realizada no início $+1 / 2$ do florescimento $(9,41)$, diferindo estatisticamente da aplicação no início, demonstrando maior proteção quando realizou-se duas aplicações de ASM nas plantas (Figura $2 \mathrm{C})$.

A ocorrência de G. zea foi responsiva às doses de ASM aplicadas, sendo verificada na maior dose $\left(37,5 \mathrm{~g} \mathrm{ha}^{-1}\right)$ a menor incidência e severidade da doença. A análise de regressão ajustável foi a linear para ambas as variáveis severidade e incidência de G. zea (Figura 3A, 3B). A equação que melhor se ajustou para a variável produtividade de grãos em resposta às doses do ativador de plantas ASM foi a quadrática, onde a maior produtividade foi alcançada na dose de 12,5 $\mathrm{g} \mathrm{ha}^{-1}$ de ASM (Figura 3C).

$\mathrm{Na}$ análise complementar, quando se comparou a melhor dose de ASM para cada variável em relação ao fungicida, não foram verificadas diferenças significativas. 

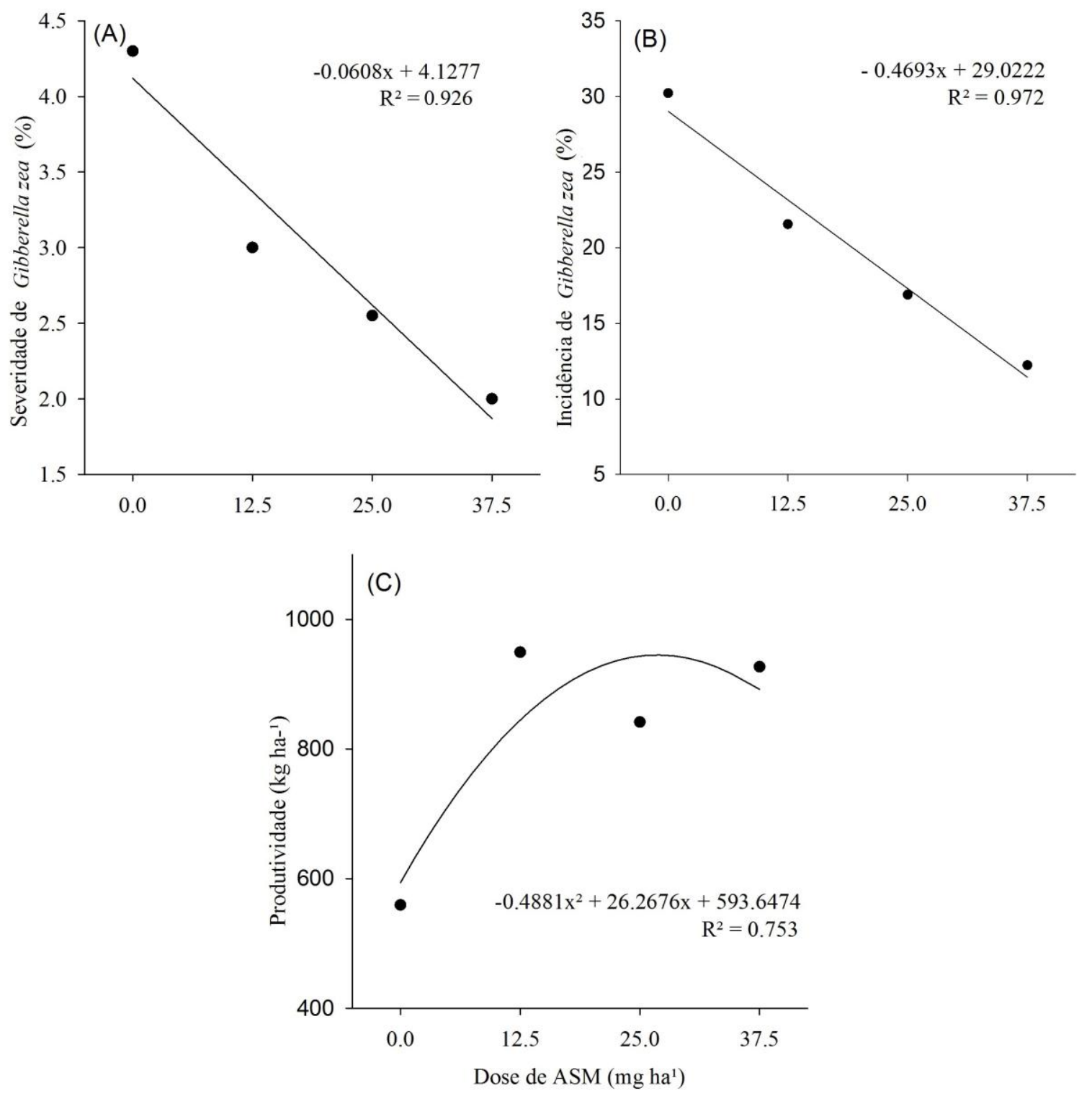

Figura 3. Porcentagem de severidade (A) e incidência (\%) (B) de Gibberella zea em grãos de trigo e produtividade $\left(\mathrm{kg} \mathrm{ha}^{-1}\right)(\mathrm{C})$ de trigo submetido a doses de ASM $(0,0 ; 12,5 ; 25,0$ e 37,5 $\left.\mathrm{g} \mathrm{ha}^{-1}\right)$ durante a antese. Percentage of severity (A) and incidence (\%) of Gibberella zea in wheat grains and yield $\left(\mathrm{kg} \mathrm{ha}^{-1}\right)(C)$ of wheat submitted to doses of ASM $(0.0 ; 12.5 ; 25.0$ and $37.5 \mathrm{~g} \mathrm{ha}^{-1}$ ) during anthesis.

As cultivares BRS 374 e Sinuelo diferiram para as variáveis número de grãos por espiga e peso de mil sementes (PMS), contudo, sem apresentar resposta significativa aos fatores isolados, corroborando com os resultados encontrados por Casa et al., (2007), no qual, testando diferentes controles químicos e épocas de aplicação, não verificaram diferença para PMS. Dessa forma, os resultados demonstram que nestes casos, a variável PMS foi mais responsiva ao genótipo do que aos tratamentos fitossanitários empregados.

A cultivar BRS 374 alcançou os maiores valores de produtividade quando comparado a Sinuelo, embora não tenha alcançado a média de produtividade esperada, de $4.733 \mathrm{~kg} \mathrm{ha}{ }^{-1}$ (CAIERÃO et al., 2013). Sugere-se que a baixa produtividade verificada para as cultivares 
testadas neste trabalho, esteja relacionada com as condições ambientais ocorridas durante o ciclo da cultura, sendo considerado um ano atípico com temperaturas elevadas (Figura 1). O excesso de calor afeta vários caracteres das plantas, que culmina com a redução do potencial produtivo da cultura, sendo que as temperaturas ideais para o crescimento das plantas de trigo são de $20{ }^{\circ} \mathrm{C}$ na germinação, $8{ }^{\circ} \mathrm{C}$ na fase vegetativa, $15{ }^{\circ} \mathrm{C}$ na fase reprodutiva e $18{ }^{\circ} \mathrm{C}$ da floração à maturação fisiológica dos grãos (SOUZA; PIMENTEL, 2013). Dessa forma, verificou-se que durante todos períodos críticos da cultura ocorreram temperaturas acima das ideais, que pode ter sido o fator que reduziu os valores de produtividade observados no presente trabalho.

Embora o rendimento médio das safras de trigo venha aumentando (CONAB, 2019), a produtividade torna-se dependente das condições ambientais e da localidade de cultivo, o que apresenta grande variação. Dessa forma, uma maior ou menor produtividade e severidade da doença ocorre em virtude de diferentes condições ambientais favoráveis ou não ao processo infectivo, bem como a variabilidade genética dos microrganismos.

A menor incidência e severidade de G. zeae observada na cultivar Sinuelo é explicada pelas suas características genéticas, por ser moderadamente suscetível à giberela (BIOTRIGO GENÉTICA, 2012). Contudo, a maior suscetibilidade à giberela foi observada na cultivar BRS 374, sendo que, segundo Cairão et al., (2013), é suscetível a giberela, moderadamente suscetível ao vírus do mosaico do trigo (SBWMV), o vírus da cevada vírus amarelo anão (BYDV) e queima das folhas (Helmintosporium sp.). Geralmente, os danos no rendimento aliados a incidência de doenças nas plantas são dependentes da cultivar/linhagem testada.

As cultivares apresentam diferenças na sua capacidade de emissão de afilhos, no seu ciclo, na arquitetura de planta e no potencial produtivo, podendo interferir na capacidade de absorção, assimilação e conversão dos fotoassimilados para a produção de grãos; além disso, a cada ano são lançados novos genótipos que, por apresentarem base genética diferenciada, podem apresentar resposta distinta à dose, à época de aplicação de nutrientes e aos defensivos (SANGOI et al., 2007). Explicando, dessa forma, as diferenças verificadas entre as cultivares testadas.

No Brasil, os danos observados na produtividade em um período de mais de duas décadas (1984 a 2010) foram estimados em média de 18,62\%, mas com grande variação entre os anos (CASA et al., 2011). A intensidade da perda na produção é determinada, geralmente, pela época em que ocorre a infecção da doença e pelo órgão afetado na planta. No caso deste trabalho, constatou-se diferença quanto à suscetibilidade à $G$. zea em função dos materiais testados e não em função da época de aplicação.

O controle químico da doença giberela é realizado eficientemente através de aplicações do fungicida trifloxistrobina+tebuconazole, como verificado por Casa et al., (2007), reduzindo significativamente a incidência de G. zea. Para este fungicida, Casa et al., (2007) comprovaram que aplicações realizadas no início do estádio fenológico da floração apresenta bons percentuais de controle da doença (redução de 53,2 a 64,6\% da severidade). A aplicação no início da antese condiciona aos produtos sistêmicos maior circulação pela planta durante o tempo, e aos preventivos proporciona um período de proteção para a planta antes que ocorra a infecção. 
O sucesso no controle da giberela também está associado ao fato das pulverizações atingirem maior número de anteras (PANISSON et al., 2002), sendo que muitas vezes pode ocorrer desuniformidade na emissão das anteras no início, e maior uniformidade na metade da antese, justificando, dessa forma, a superioridade da eficiência quando se realizam duas aplicações (início + metade) do ativador de plantas ASM.

No presente trabalho, constatou-se que duas aplicações de ASM (início + 1/2 do florescimento) são eficientes na redução do número de espiguetas estéreis por espiga, diferindo significativamente quando comparado a apenas uma aplicação no início da floração. Contudo, ressalta-se que o ASM não tem ação direta sobre o fungo, mas sim induz mecanismos bioquímicos e estruturais envolvidas no processo, como a produção de substâncias de defesa da planta, promovendo defesa do vegetal à infecções; não apresentando risco de aquisição de resistência por parte do fungo. É ideal que produtos que ativem os mecanismos de defesa da planta sejam aplicados preventivamente, pois uma planta injuriada necessita de maiores taxas metabólicas para manutenção e respiração, resultando muitas vezes em redução do desempenho.

O ácido salicílico (AS) atua na manifestação da SAR (do inglês "resistência sistêmica adquirida"), um mecanismo de defesa induzível que confere resistência a um amplo espectro de patógenos (OLIVEIRA et al., 2016). Plantas de Arabidopsis pré-tratadas com AS também apresentaram redução da severidade de $F$. graminearum por expressar genes da patogênese $(P R)$ (MAKANDAR et al., 2012). Pesquisas com plantas com genes mutantes mostram que o AS regula os mecanismos de resistência através da SAR (resposta de hipersensibilidade), atuando na expressão de genes responsáveis pelo acúmulo de espécies reativas de oxigênio no apoplasto, ocasionando síntese de lignina e morte celular das células vizinhas; além da síntese de compostos fenólicos (VLOT et al., 2009).

Espigas de trigo infectadas com G. zea acumulam elevados níveis de AS suprindo a defesa do trigo contra esse patógeno, fato que comprova a possível ação do ASM contra $G$. zea (DING et al., 2011), corroborando com os dados deste experimento. Dessa forma, quando aplicado na forma exógena é capaz de induzir aumento da síntese do próprio AS nos tecidos vegetais (OLIVEIRA et al., 2016), promovendo síntese de substâncias de defesa antes que ocorra processo infectivo, fazendo com que a planta mantenha-se protegida, resultando em maior acúmulo de reservas destinadas para a produção em vez de ser destinadas à defesa contra patógenos.

Efeitos positivos da aplicação do indutor de resistência ASM já foram comprovados na cultura do trigo por reduzir a intensidade de algumas doenças como Oidium sp. (CHAIN et al., 2009) e Gibberella zea (MAKAMAR et al., 2010), e também para outros patossistemas como Colletotrichum lindemuthianum, em plantas de feijão (CAMPOS et al., 2009) e Monilinia fructicola, na pós-colheita de pêssegos (BARRETO et al., 2016). Aplicação do AS in vitro condicionaram potencial de controle do crescimento micelial de Scleriotinia sclerotium e Rhizoctonia solani em beterraba, feijão e tomate, respectivamente, além de aumentar a atividade da enzima $\beta$-1,3-glucanase em plântulas (BERTONCELLI et al., 2016; BERTONCELLI et al., 2015). 
Os indutores de resistência recomendados para o controle de doenças não afetam o meio ambiente devido à rápida degradação da molécula e também por proporcionar menor pressão de seleção na população do patógeno (OLIVEIRA et al., 2016). Neste sentido, para este experimento nas condições do Rio Grande do Sul no ano de 2015, as aplicações de ASM na cultura do trigo apresentaram resultados positivos, pois quando as doses do ASM foram comparadas com o fungicida trifloxistrobina+tebuconazol, para as variáveis porcentagem de incidência, severidade e produtividade, não ocorreram diferenças significativas, sugerindo inserção do ASM no manejo integrado de G. zea para a cultura do trigo. Essas informações podem modificar o atual cenário do manejo fitossanitário para a cultura do trigo, uma vez que os princípios ativos utilizados têm mostrado resultados inconsistentes para giberela.

\section{CONCLUSÕES}

Duas aplicações de ASM, realizadas no início + $1 / 2$ da antese condicionam menor número de espiguetas estéreis na cultura do trigo.

A dose de 37,5 $\mathrm{g} \mathrm{ha}^{-1}$ de ASM proporciona baixos percentuais de incidência e severidade de Gibberella zea em grãos de trigo, sugerindo inserção do ASM no manejo integrado da doença.

A dose de 12,5 $\mathrm{g} \mathrm{ha}^{-1}$ ASM condiciona a maior produtividade da cultura do trigo.

\section{REFERÊNCIAS BIBLIOGRÁFICAS}

BARRETO, C. F.; MORENO, M. B.; SILVA, P. S.; BARBOSA, M. M.; FACHINELLO, J. C. Ácido salicílico na pós - colheita para reduçã o de podridão parda e manutenção qualidade de pêssego 'chiripá'. Revista Iberoamericana de Tecnología Postcosecha, Hermosillo, v. 17, n. 1, p.50-57, 2016.

BERTONCELli, D. J.; MAZARO, S. M.; ROCHA, R. D. C. D. S.; DALACOSTA, N. L.; LEWANDOWSKI, A.; JUNIOR, A. W. Salicylic acid in the induction of resistance to beet seedling damping-off and antifungal activity against Fusarium sp., in vitro. Semina: Ciências Agrárias, Londrina, v. 37, n. 1, p.67-76, 2016.

BERTONCELlI, D. J.; MAZARO, S. M.; ROCHA, R. D. C. D. S.; POSSENTI, J. C.; DOS SANTOS REY, M.; ZORZZI, I. C. Ácido salicílico na indução de resistência a doenças em pepino e controle de Pythium sp. in vitro. Revista de Ciências Agroveterinárias, Lages, v. 14, n. 2, p.124-131, 2015.

BIOTRIGO GENÉTICA. TBIO Sinuelo: características agronômicas. Passo Fundo; Campo Mourão, 2012. Disponível em: http://www.biotrigo.com.br/cultivares/internaCultivar.php?empresa=1\&id=21. Acesso em: 01 jun. 2016.

BRASIL. Ministério da Agricultura, Pecuária e Abastecimento. Coordenação Geral de Agrotóxicos e Afins. Sistemas de Agrotóxicos Fitossanitários - AGROFIT. Brasília, 2018. 
Disponível em: http://agrofit.agricultura.gov.br/agrofit_cons/principal_agrofit_cons. Acesso em: 21 mar. 2018.

BRASIL. Ministério da Agricultura, Pecuária e Abastecimento. Regras para análise de sementes. Brasília, 2009. 395 p. Disponível em: http://www.bs.cca.ufsc.br/publicacoes/regras\%20analise\%20sementes.pdf. Acesso em: 25 jun. 2016.

CAIERÃO, E.; SÓ E SILVA, M.; SCHEEREN, P. L.; EICHELBERGER, L.; NASCIMENTO JÚNIOR, A. D.; GUARIENTI, E. M. BRS 374-wheat cultivar. Crop Breeding and Applied Biotechnology, Viçosa, v. 13, n. 3, p.212-214, 2013.

CAMPOS, A. D. Considerações sobre indução de resistência a patógenos em plantas. Pelotas: Embrapa Clima Temperado, 2009. 28 p.

CASA, R. T.; BOGO, A.; MOREIRA, E. N.; KUHNEM, P. R. Época de aplicação e desempenho de fungicidas no controle da giberela em trigo. Ciência Rural, Santa Maria, v. 37, n. 6, p.1558-1563, 2007.

CASA, R. T.; KUHNEM, P. R. Danos causados nos hospedeiros. In: REIS, E. M. (Ed). Seminário sobre giberela em cerais de inverno: coletânea de trabalhos Passo Fundo: Bertier. 2011. p. 131-164.

CHAIN, F.; CÔTÉ-BEAULIEU, C.; BELZILE, F.; MENZIES, J. G.; BÉLANGER, R. R. A comprehensive transcriptomic analysis of the effect of silicon on wheat plants under control and pathogen stress conditions. Molecular Plant-Microbe Interactions, Saint Paul, v. 22, n.11, p.1322-1330, 2009.

COMPANHIA NACIONAL DE ABASTECIMENTO - CONAB. Acompanhamento da safra brasileira de grãos. v.6 - Safra 2018/19- n.4 - Monitoramento agrícola. Brasília, 2019. $126 \mathrm{p}$.

DEL PONTE, E. M.; SPOLTI, P.; WARD, T. J.; GOMES, L. B.; NICOLLI, C. P.; KUHNEM, P. R.; SILVA, C. N.; TESSMANN, D. J. Regional and field-specific factors affect the composition of Fusarium head blight pathogens in subtropical no-till wheat agroecosystem of Brazil. Phytopathology, Saint Paul, v. 105, n. 2, p.246-254, 2015.

DING, L.; XU, H.; YI, H.; YANG, L.; KONG, Z.; ZHANG, L.; XUE, S.; JIA, H.; MA, Z. Resistance to hemi-biotrophic $F$. graminearum infection is associated with coordinated and ordered expression of diverse defense signaling pathways. Plos One, San Francisco, v. 6, n. 4, p.e19008, 2011.

EMPRESA BRASILEIRA DE PESQUISA AGROPECUÁRIA - EMBRAPA. Sistema Brasileiro de Classificação de Solos. 3. ed. Rio de Janeiro: EMBRAPA-SPI, 2013. 306 p.

FERREIRA, D. F. Análises estatísticas por meio do Sisvar para Windows versão 4.0. In: REUNIÃO ANUAL DA REGIÃO BRASILEIRA DA SOCIEDADE INTERNACIONAL DE BIOMETRIA, 45, 2000. Anais [....] São Carlos, SP: SIB, 2000. p. 255-258. 
GILBERT, J.; HABER, S. Overview of some recent research developments in Fusarium head blight of wheat. Canadian Journal of Plant Pathology, Ontario, v. 35, n. 5, p.149-174, 2013.

KLIX, M. B.; VERREET, J. A.; BEYER, M. Comparison of the declining triazole sensitivity of Gibberella zeae and increased sensitivity achieved by advances in triazole fungicide development. Crop Protection, Amsterdam, v. 26, n. 4, p. 683-690, 2007.

LUCAS, J. A.; HAWKINS, N. J.; FRAAIJE, B. A. The evolution of fungicide resistance. Advances in Applied Microbiology, San Diego, v. 90, p. 29-92, 2015.

MAKANDAR, R.; NALAM, V. J.; LEE, H.; TRICK, H. N.; DONG, Y.; SHAH, J. Salicylic acid regulates basal resistance to Fusarium head blight in wheat. Molecular Plant-Microbe Interactions, Saint Paul, v. 25, n. 3, p.431-439, 2012.

MENDOZA, D.; CUASPUD, O.; ARIAS, J. P.; RUIZ, O.; ARIAS, M. Effect of salicylic acid and methyl jasmonate in the production of phenolic compounds in plant cell suspension cultures of Thevetia peruviana. Biotechnology Reports, Amsterdam, v. 19, p. e00273, 2018.

OLIVEIRA, M. D. M.; VARANDA, C. M. R.; FÉLIX, M. R. F. Induced resistance during the interaction pathogen $\mathrm{x}$ plant and the use of resistance inducers. Phytochemistry letters, Amsterdam, v. 15, p.152-158, 2016.

PANISSON, E. D. I. V. A. N.; REIS, E. M.; BOLLER, W. A. L. T. E. R. Efeito de época, do número de aplicações e de doses de fungicida no controle da giberela em trigo. Fitopatologia Brasileira, Fortaleza, v.27, n. 5, p.495-499, 2002.

PAUL, P. A.; LIPPS, P. E.; HERSHMAN, D. E.; MCMULLEN, M. P.; DRAPER, M. A.; MADDEN, L. V. Efficacy of triazole-based fungicides for Fusarium head blight and deoxynivalenol control in wheat: a multivariate meta-analysis. Phytopathology, Saint Paul, v. 98, n. 8, p.999-1011, 2008.

QUEIROZ, E. R.; ABREU, C. M. P.; SANTOS, C. M.; SIMÃO, A. A. Composição química e fitoquímica das farinhas da casca e da semente de lichias (Litchi chinensis Sonn) cultivar 'Bengal'. Ciência Rural, Santa Maria, v. 45, n. 2, p.329-334, 2015.

REUNIÃO DA COMISSÃO SULBRASILEIRA DE PESQUISA DE TRIGO, 37, 2005, Cruz Alta. Indicações técnicas da Comissão Sul-Brasileira de Pesquisa de Trigo: trigo e triticale. 2005. Cruz Alta: FUNDACEP, 2005. 159 p.

SANGOI, L.; BERNS, A. C.; DE ALMEIDA, M. L.; ZANIN, C. G.; SCHWEITZER, C. Características agronômicas de cultivares de trigo em resposta à época da adubação nitrogenada de cobertura. Ciência Rural, Santa Maria, v. 37, n. 6, p.1564-1570, 2007.

SOUZA, M. A.; PIMENTEL, A. J. B. Estratégias de seleção para melhoramento do trigo com tolerância ao estresse por calor. Informe Agropecuário, Belo Horizonte, v. 34, p.30-39, 2013.

SPOLTI, P.; DEL PONTE, E. M. Agressividade diferencial de espécies do complexo Fusarium graminearum em interação com o fungicida tebuconazole na redução do rendimento de trigo. Ciência Rural, Santa Maria, v. 43, n. 9, p.1569-1575, 2013. 
TRALAMAZZA, S. M.; BEMVENUTI, R. H.; ZORZETE, P.; DE SOUZA GARCIA, F.; CORREIA, B. Fungal diversity and natural occurrence of deoxynivalenol and zearalenone in freshly harvested wheat grains from Brazil. Food Chemistry, London, v. 196, p.445-456, 2016.

VLOT, A. C.; DEMPSEY, D. A.; KLESSIG, D. F. Salicylic acid, a multifaceted hormone to combat disease. Annual Review of Phytopathology, Palo Alto, v. 47, n. 1, p.177-206, 2009.

WEGULO, S. N.; BAEZIGER, P. S.; NOPSA, J. H.; BOCKUS, W. W; HALLEN-ADAMS, H. Management of fusarium head blight of wheat and barley. Crop Protection, v. 95, n. 5, p.554-560, 2011. 